Article

\title{
Suberitamides A-C, Aryl Alkaloids from a Pseudosuberites sp. Marine Sponge that Inhibit Cbl-b Ubiquitin Ligase Activity
}

\author{
Chang-Kwon Kim ${ }^{1}\left(\mathbb{D}\right.$, Dongdong Wang ${ }^{1}{ }^{(D}$, Brice A. P. Wilson ${ }^{1}\left({ }^{1}\right.$, Josep Saurí ${ }^{2}$, Donna Voeller ${ }^{3}$, \\ Stanley Lipkowitz ${ }^{3}$, Barry R. O'Keefe ${ }^{1,4}$ and Kirk R. Gustafson ${ }^{1, *(\mathbb{D}}$ \\ 1 Molecular Targets Program, Center for Cancer Research, National Cancer Institute, \\ Frederick, MD 21702-1201, USA; chang-kwon.kim@nih.gov (C.-K.K.); dongdong.wang@nih.gov (D.W.); \\ brice.wilson@nih.gov (B.A.P.W.); okeefeba@mail.nih.gov (B.R.O.) \\ 2 Structure Elucidation Group, Analytical Research and Development, Merck \& Co., Inc., \\ Boston, MS 02115, USA; josep.sauri.jimenez@merck.com \\ 3 Women's Malignancies Branch, Center for Cancer Research, National Cancer Institute, \\ Bethesda, MD 20892-1578, USA; Donna.Voeller@nih.gov (D.V.); lipkowis@mail.nih.gov (S.L.) \\ 4 Natural Products Branch, Developmental Therapeutics Program, Division of Cancer Treatment and \\ Diagnosis, National Cancer Institute, Frederick, MD 21701-1201, USA \\ * Correspondence: gustafki@mail.nih.gov
}

Received: 29 September 2020; Accepted: 22 October 2020; Published: 28 October 2020

\begin{abstract}
Three new aryl alkaloids named suberitamides A-C (1-3), were isolated from an extract of the marine sponge Pseudosuberites sp. collected along the coast of North Carolina. Their planar structures were established by extensive nuclear magnetic resonance (NMR) and mass spectrometry (MS) analysis. To assign the challenging relative configuration of the saturated five-membered ring in suberitamide $\mathrm{A}(\mathbf{1})$, a simple and efficient NMR protocol was applied that is based on the analysis of 2- and 3-bond ${ }^{1} \mathrm{H}_{-}{ }^{13} \mathrm{C}$ spin-spin coupling constants using a PIP (pure in-phase) HSQMBC (heteronuclear single quantum multiple bond correlation) IPAP (in-phase and anti-phase) experiment. Suberitamides A (1) and B (2) inhibited Cbl-b, an E3 ubiquitin ligase that is an important modulator of immune cell function, with $\mathrm{IC}_{50}$ values of approximately $11 \mu \mathrm{M}$.
\end{abstract}

Keywords: marine sponge; Pseudosuberites sp.; suberitamides; PIP HSQMBC IPAP; Cbl-b ubiquitin ligase inhibition

\section{Introduction}

The Casitas B-lineage lymphoma proto-oncogene $b(\mathrm{Cbl}-\mathrm{b})$ is a RING finger E3 ubiquitin ligase that has been identified as a negative regulator of T-cells, NK cells, B cells, and different types of myeloid cells [1-4]. It also regulates innate immune responses and plays an important role in host defense toward pathogens [5]. Since Cbl-b suppresses activation of diverse immunologic responses, it may represent a potential therapeutic target for the management of human immune-related disorders such as autoimmune diseases and allergic inflammation, as well as impacting the immune response to infections and tumors [6,7]. Compounds that can inhibit the ubiquitin ligase activity of Cbl-b may provide lead structures for the development of immune-modulating therapeutic interventions.

In conjunction with ongoing NCI (National Cancer Institute) anticancer natural product discovery efforts $[8,9]$, the extract of a North Carolina collection of the marine sponge Pseudosuberites sp. was screened, and showed significant activity in an assay for inhibitors of Cbl-b ubiquitin ligase [10]. Bioassay-guided fraction of the extract provided three new aryl alkaloids that were named suberitamides A-C (1-3) (Figure 1). The lead compound, suberitamide A (1) possesses a saturated five-membered 
ring which exists as numerous puckered conformations due to the inherent conformational flexibility of these rings. Assigning the relative configurations of contiguous stereogenic centers in these systems can be problematic, but for $\mathbf{1}$ they were established by a simple and effective $J$-based methodology using the PIP (pure in-phase) HSQMBC IPAP experiment [11]. This NMR technique allows the accurate determination of heteronuclear coupling constants $\left({ }^{n} J_{\mathrm{CH}}, \mathrm{n}>1\right)$ in a broadband manner while providing easy-to-analyze, pure in-phase lineshapes, and it is particularly useful for measuring couplings between protons and non-protonated carbons. We successfully applied this methodology to determine the relative configuration for the saturated five-membered ring in suberitamide A (1). Suberitamides B (2) and C (3) were readily identified as symmetric molecules from their NMR and ESI-MS data. Detailed 2D NMR analysis revealed suberitamide B (2) as a more highly substituted analogue of $\mathbf{1}$ with a pyrrole moiety in the central position of the molecule, while suberitamide C (3) was an oxidized, ring-opened homologue of $\mathbf{1}$. Compounds $\mathbf{1}$ and $\mathbf{2}$ inhibited Cbl-b enzymatic activity in an in-vitro ubiquitin ligase assay.

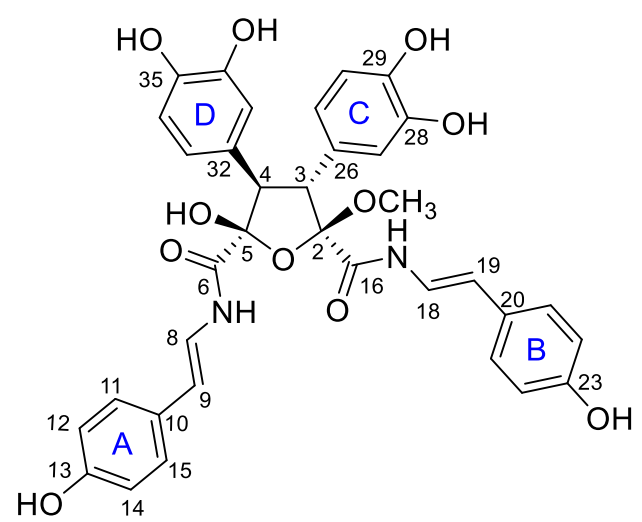

1<smiles>O=C(N/C=C/c1ccc(O)cc1)c1c(-c2ccc(O)c(O)c2)c(-c2ccc(O)c(O)c2)c(C(=O)N/C=C/c2ccc(O)cc2)n1C[12F]</smiles>

2<smiles>O=C(N/C=C/c1ccc(O)cc1)C(=O)C(=O)C(C(=O)N/C=C/c1ccc(O)cc1)C(c1ccc(O)c(O)c1)c1ccc(O)c(O)c1</smiles>

3

Figure 1. Structures of suberitamides A-C (1-3).

\section{Results and Discussion.}

The molecular formula of suberitamide A (1) was determined by HRESIMS to be $\mathrm{C}_{35} \mathrm{H}_{32} \mathrm{~N}_{2} \mathrm{O}_{11}$, with 21 degrees of unsaturation. Detailed examination of the ${ }^{1} \mathrm{H}$ and ${ }^{13} \mathrm{C}$ NMR data (Table 1 ) aided by 2-D NMR experiments, revealed that this compound possessed two para-hydroxystyrylamide ( $p$ HSA) moieties (A and B rings). The ${ }^{1} \mathrm{H}$ NMR spectrum (DMSO- $d_{6}$ ) indicated the presence of two trans disubstituted double bonds with signals at $\delta_{\mathrm{H}} 7.29(1 \mathrm{H}, \mathrm{dd}, J=14.6,10.2 \mathrm{~Hz})$ and $6.43(1 \mathrm{H}, \mathrm{d}$, $J=14.6 \mathrm{~Hz})$, along with $7.04(1 \mathrm{H}, \mathrm{dd}, J=14.6,10.2 \mathrm{~Hz})$ and $6.29(1 \mathrm{H}, \mathrm{d}, J=14.6 \mathrm{~Hz})$. Incorporation of these olefins into two enamide functionalities was apparent from COSY correlations between $\mathrm{H}-8 / 7-\mathrm{NH}$ $\left(\delta_{\mathrm{H}} 10.52\right)$ and $\mathrm{H}-18 / 17-\mathrm{NH}\left(\delta_{\mathrm{H}} 10.50\right)$, while two non-equivalent $p$-hydroxyphenyl groups were also established with $\delta_{\mathrm{H}} 7.24(2 \mathrm{H}, \mathrm{d}, J=8.4 \mathrm{~Hz})$ coupled to $6.72(2 \mathrm{H}, \mathrm{d}, J=8.4 \mathrm{~Hz})$ and $7.18(2 \mathrm{H}, \mathrm{d}, J=8.4 \mathrm{~Hz})$ coupled to $6.70(2 \mathrm{H}, \mathrm{d}, J=8.4 \mathrm{~Hz})$. Furthermore, two typical ABM spin systems at $\delta_{\mathrm{H}} 6.55(1 \mathrm{H}, \mathrm{d}$, $J=1.8 \mathrm{~Hz}), 6.51(1 \mathrm{H}, \mathrm{d}, J=8.4 \mathrm{~Hz})$, and $6.38(1 \mathrm{H}, \mathrm{dd}, J=8.4,1.8 \mathrm{~Hz})$, along with $6.52(1 \mathrm{H}, \mathrm{d}, J=1.8 \mathrm{~Hz})$, $6.50(1 \mathrm{H}, \mathrm{d}, J=8.4 \mathrm{~Hz})$ and $6.36(1 \mathrm{H}, \mathrm{dd}, J=8.4,1.8 \mathrm{~Hz})$ were indicative of two dihydroxyphenyl 
groups (rings $\mathrm{C}$ and D) in $\mathbf{1}$. Assignment of the four aryl substituents in $\mathbf{1}$ was consistent with all of the observed HMBC correlations (Figure 2).

Table 1. ${ }^{13} \mathrm{C}$ NMR $(150 \mathrm{MHz})$ and ${ }^{1} \mathrm{H}$ NMR $(600 \mathrm{MHz})$ Data for Suberitamide A (1).

\begin{tabular}{|c|c|c|c|c|}
\hline Position & $\delta_{\mathrm{C}}{\text { (type })^{a}}^{a}$ & $\delta_{\mathrm{H}}(\mathrm{J} \text { in } \mathrm{Hz})^{a}$ & $\delta_{\mathrm{C}}{\text { (type })^{b}}^{b}$ & $\delta_{\mathrm{H}}(\mathrm{J} \text { in } \mathrm{Hz})^{b}$ \\
\hline 2 & $109.1 \mathrm{C}$ & & $110.9 \mathrm{C}$ & \\
\hline $2-\mathrm{OCH}_{3}$ & $51.6, \mathrm{CH}_{3}$ & $3.40, \mathrm{~s}$ & $52.6, \mathrm{CH}_{3}$ & $3.52, \mathrm{~s}$ \\
\hline 3 & $53.3, \mathrm{CH}$ & $4.09, \mathrm{~d}(13.8)$ & $55.4, \mathrm{CH}$ & $4.22, \mathrm{~d}(13.8)$ \\
\hline 4 & $54.6, \mathrm{CH}$ & $3.91, \mathrm{~d}(13.8)$ & $56.3, \mathrm{CH}$ & $4.04, \mathrm{~d}(13.8)$ \\
\hline 5 & $102.3 \mathrm{C}$ & & $103.8 \mathrm{C}$ & \\
\hline $5-\mathrm{OH}$ & & $7.40, \mathrm{~s}$ & & \\
\hline 6 & $169.4, \mathrm{~s}$ & & $171.6, \mathrm{~s}$ & \\
\hline 7-NH & & $10.52, \mathrm{~d}(10.2)$ & & \\
\hline 8 & $120.2, \mathrm{CH}$ & $\begin{array}{c}7.29, \mathrm{dd}(14.6 \\
10.2)\end{array}$ & $120.7, \mathrm{CH}$ & 7.37, d (14.6) \\
\hline 9 & $114.8, \mathrm{CH}$ & $6.43, \mathrm{~d}(14.6)$ & $117.2, \mathrm{CH}$ & $6.40, \mathrm{~d}(14.6)$ \\
\hline 10 & 126.9, C & & $128.9, \mathrm{C}$ & \\
\hline 11,15 & $126.8, \mathrm{CH}$ & $7.24, \mathrm{~d}(8.4)$ & 128.0, $\mathrm{CH}$ & $7.25, \mathrm{~d}(8.4)$ \\
\hline 12,14 & $115.6, \mathrm{CH}$ & $6.72, \mathrm{~d}(8.4)$ & $116.6, \mathrm{CH}$ & $6.75, \mathrm{~d}(8.4)$ \\
\hline 13 & 156.4, C & & $157.8, \mathrm{C}$ & \\
\hline $13-\mathrm{OH}$ & & $9.47, \mathrm{~s}$ & & \\
\hline 16 & 166.0, C & & $168.6, \mathrm{C}$ & \\
\hline 17-NH & & $10.50, \mathrm{~d}(10.2)$ & & \\
\hline 18 & $120.1, \mathrm{CH}$ & $\begin{array}{c}\text { 7.04, dd (14.6, } \\
10.2)\end{array}$ & $120.5, \mathrm{CH}$ & 7.10, d (14.6) \\
\hline 19 & $114.3, \mathrm{CH}$ & $6.29, \mathrm{~d}(14.6)$ & $117.1, \mathrm{CH}$ & 6.35, d (14.6) \\
\hline 20 & $126.9, \mathrm{C}$ & & $128.8, \mathrm{C}$ & \\
\hline 21,25 & 126.7, $\mathrm{CH}$ & $7.18, \mathrm{~d}(8.4)$ & $128.0, \mathrm{CH}$ & $7.20, \mathrm{~d}(8.4)$ \\
\hline \multirow[t]{2}{*}{22,24} & $115.6, \mathrm{CH}$ & $6.70, \mathrm{~d}(8.4)$ & $116.5, \mathrm{CH}$ & $6.73, \mathrm{~d}(8.4)$ \\
\hline & 156.3, C & & 157.7, C & \\
\hline $23-\mathrm{OH}$ & & $9.44, \mathrm{~s}$ & & \\
\hline 26 & 124.8, C & & $126.5, \mathrm{C}$ & \\
\hline 27 & $115.8, \mathrm{CH}$ & $6.52, \mathrm{~d}(1.8)$ & $116.7, \mathrm{CH}$ & $6.66, \mathrm{~d}(1.8)$ \\
\hline 28 & $144.4, \mathrm{C}$ & & $146.1, \mathrm{C}$ & \\
\hline $28-\mathrm{OH}$ & & $8.71, \mathrm{~s}$ & & \\
\hline 29 & 144.5, C & & $145.8, \mathrm{C}$ & \\
\hline $29-\mathrm{OH}$ & & $8.74, \mathrm{~s}$ & & \\
\hline 30 & 115.0, $\mathrm{CH}$ & $6.50, \mathrm{~d}(8.4)$ & $115.9, \mathrm{CH}$ & $6.60, \mathrm{~d}(8.4)$ \\
\hline 31 & $119.2, \mathrm{CH}$ & $\begin{array}{c}6.36, \mathrm{dd}(8.4, \\
1.8)\end{array}$ & $121.2, \mathrm{CH}$ & $6.54, \mathrm{dd}(8.4,1.8)$ \\
\hline 32 & 125.0, C & & $126.6, \mathrm{C}$ & \\
\hline 33 & $116.6, \mathrm{CH}$ & $6.55, \mathrm{~d}(1.8)$ & $117.5, \mathrm{CH}$ & $6.69, \mathrm{~d}(1.8)$ \\
\hline 34 & 144.7, C & & 145.7, C & \\
\hline $34-\mathrm{OH}$ & & $8.68, \mathrm{~s}$ & & \\
\hline 35 & $144.6, \mathrm{C}$ & & $145.9, \mathrm{C}$ & \\
\hline $35-\mathrm{OH}$ & & $8.69, \mathrm{~s}$ & & \\
\hline 36 & $115.2, \mathrm{CH}$ & $6.51, \mathrm{~d}(8.4)$ & $116.2, \mathrm{CH}$ & $6.61, \mathrm{~d}(8.4)$ \\
\hline 37 & $120.1, \mathrm{CH}$ & $\begin{array}{c}6.38, \mathrm{dd}(8.4 \\
1.8)\end{array}$ & $122.1, \mathrm{CH}$ & $6.52, \mathrm{dd}(8.4,1.8)$ \\
\hline
\end{tabular}


The structural fragments assembled thus far accounted for 20 of the 21 degrees of unsaturation in 1. The last unsaturation equivalent was identified as an oxolane at the core of the molecule. The composition and connectivity of the central five-membered ring was confirmed by proton-proton coupling between $\mathrm{H}-3\left(\delta_{\mathrm{H}} 4.09, \mathrm{~d}, J=13.8 \mathrm{~Hz}\right)$ and $\mathrm{H}-4\left(\delta_{\mathrm{H}} 3.91, \mathrm{~d}, J=13.8 \mathrm{~Hz}\right)$ and $\mathrm{HMBC}$ correlations between H-3/C-26/C-27/C-2/C-16, H-4/C-32/C-33/C-5/C-6, H-27/C-3, H-31/C-3, H-33/C-4, and H-37/C-4. Finally, a methyl acetal $\left(\delta_{\mathrm{H}} 3.403 \mathrm{H}, \mathrm{s}\right)$ group at $\mathrm{C}-2\left(\delta_{\mathrm{C}} 109.1\right)$ and a hemiacetal $\left(\delta_{\mathrm{H}} 7.40 \mathrm{OH}\right.$, s) group at C-5 $\left(\delta_{\mathrm{C}} 102.3\right)$ were confirmed by HMBC correlations between $2-\mathrm{OCH}_{3} / \mathrm{C}-2$ and $5-\mathrm{OH} / \mathrm{C}-4 / \mathrm{C}-5 / \mathrm{C}-6$. To verify the positions of the hemiacetal and acetal carbons, several long-range heteronuclear correlation NMR experiments were conducted including $\mathrm{HMBC}$ optimized for $J_{\mathrm{CH}}=3.5 \mathrm{~Hz}$ or $J_{\mathrm{CH}}=2.0 \mathrm{~Hz}$, and an LR-HSQMBC experiment optimized for $J_{\mathrm{CH}}=2.0 \mathrm{~Hz}$ [12]. As a result, we confirmed 4-bond correlations from H-27 and H-31 to C-2, as well as H-33 and H-37 to C-5 (Figure 1). This completed assignment of the planar structure of suberitamide A (1), which consists of a central oxolane ring containing hemiacetal and methyl acetal groups, with the para-hydroxystyrylamide carbonyls attached at C-2 and C-5, and the dihydroxy aromatic rings linked at C-3 and C-4.
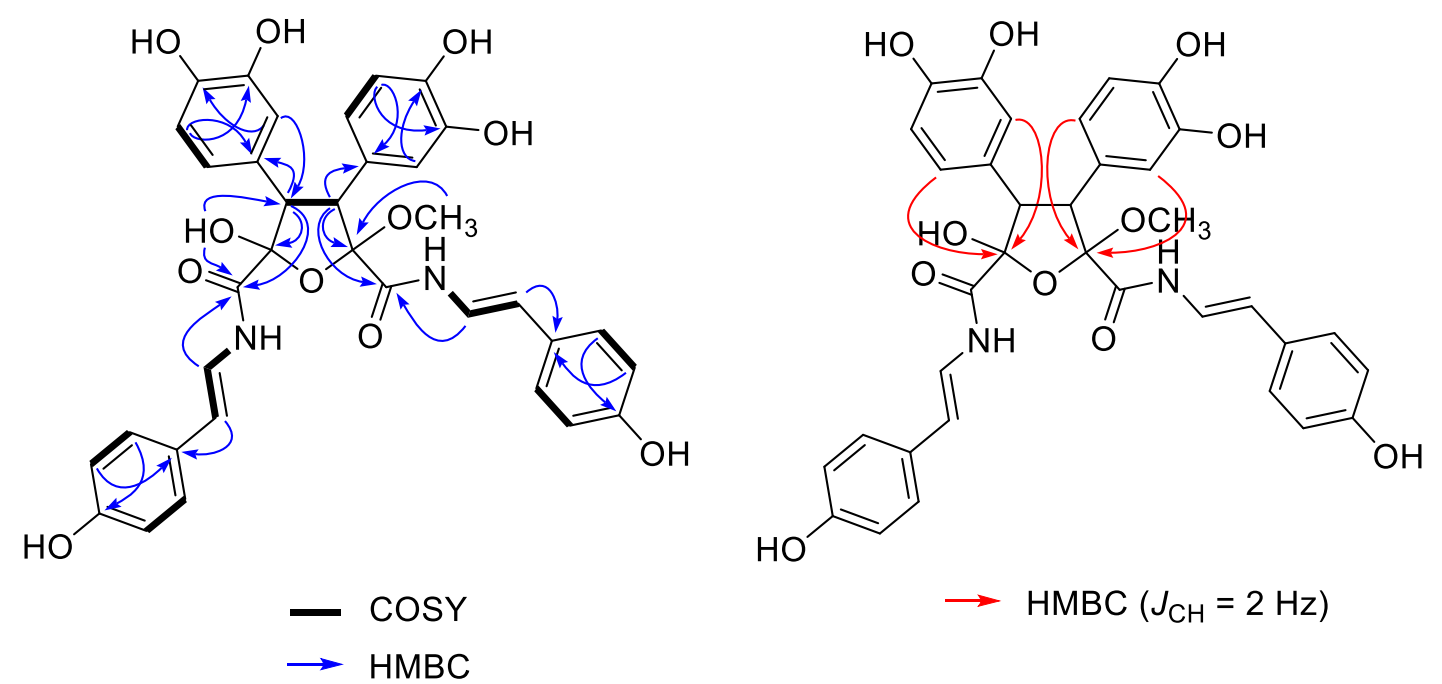

Figure 2. Selected 2D NMR correlations for suberitamide A (1). HMBC (heteronuclear multiple bond correlation) experiments were optimized for $J_{\mathrm{CH}}=8.0 \mathrm{~Hz}$ (blue arrows, measured in DMSO- $d_{6}$ ) or $J_{\mathrm{CH}}$ $=2.0 \mathrm{~Hz}$ (red arrows, measured in $\mathrm{CD}_{3} \mathrm{OD}$ ).

The oxolane ring of 1 possessed four contiguous stereogenic centers at C-2, C-3, C-4, and C-5. The relative configuration of this type of five-membered ring system is often difficult to assign by conventional NMR analyses (NOEs, ${ }^{1} \mathrm{H}-{ }^{1} \mathrm{H}$ couplings) due to conformational flexibility and puckering of the ring [13]. While the 1,3-cis NOE effect is generally a reliable tool for assigning relative configuration in a system like this, NOEs between vicinal protons on five-membered rings are not necessarily diagnostic. A J-based approach to determine the relative configuration in substituted five-membered oxolane rings using the analysis of homonuclear and heteronuclear $J$ couplings, and quantum mechanical DFT methods has recently been described [14,15]. It established specific ranges and thresholds, based on the magnitude of 2- and 3-bond H/C heteronuclear couplings, that defined the relative orientation of substituents around the ring system.

We initially measured selective 1D ROESY correlations with $\mathbf{1}$ and observed positive interactions between $5-\mathrm{OH} / \mathrm{H}-3, \mathrm{H}-3 / 2-\mathrm{OCH}_{3}$, and $\mathrm{H}-4 / 7-\mathrm{NH}$ in DMSO- $d_{6}$ (Figure 2A and Supporting Information). Thus, the configuration of the oxolane ring of 1 should have $\mathrm{H}-3 / \mathrm{H}-4-$ trans and $5-\mathrm{OH} / \mathrm{H}-3$-cis. Support for the $\mathrm{H}-3 / \mathrm{H}-4-$ trans relationship, in which there is approximately a $180^{\circ}$ dihedral angle between $\mathrm{H}-3$ and $\mathrm{H}-4$, was provided by comparing the H-3/H-4 coupling constant we measured $(13.8 \mathrm{~Hz})$ with that calculated using MestReJ $(13.86 \mathrm{~Hz})$ for a similar ${ }^{3} \mathrm{~J}_{\mathrm{HH}}$ with a $180^{\circ}$ dihedral angle (Figure $2 \mathrm{~B}$ and Supporting Information) [16]. 
For the $J$-based analysis, we measured the ${ }^{1} \mathrm{H}_{-}{ }^{13} \mathrm{C}$ heteronuclear couplings using an HSQC-HECADE (heteronuclear couplings from ASSCI-domain experiments with E.COSY-type cross peaks) experiment (Supporting Information) $[17,18]$. This provided complimentary evidence for a trans orientation between $\mathrm{H}-3$ and $\mathrm{H}-4$ with characteristic large couplings measured for ${ }^{2} J_{\mathrm{C} 3, \mathrm{H} 4}$ $(-7.1 \mathrm{~Hz})$ and ${ }^{2} J_{\mathrm{C} 4, \mathrm{H} 3}(-9.6 \mathrm{~Hz})$. However, with this experiment it was not possible to measure the desired ${ }^{3} J_{\mathrm{C}, \mathrm{H}}$ couplings between $\mathrm{H}-4 / \mathrm{C}-6$ and $\mathrm{H}-3 / \mathrm{C}-16$ because the carbons are nonprotonated. Thus, we employed a PIP (pure in-phase) HSQMBC IPAP experiment which allows accurate extraction of proton-carbon coupling constants, ${ }^{\mathrm{n}} J_{\mathrm{CH}}(\mathrm{n}>1)$ for nonprotonated carbons [11]. For suberitamide A (1), we initially acquired both the $8.0 \mathrm{~Hz}$ optimized IP (in-phase) and AP (anti-phase) PIP-HSQMBC spectra (Supplementary Materials, Figures S10-S13). Then, we applied the IPAP methodology which involves adding the in-phase and anti-phase components (IP + AP) or alternately subtracting the anti-phase component (IP - AP) of the two datasets. After executing the addition/subtraction steps, 1D slices were extracted from the IP + AP and IP - AP datasets at the frequencies of the carbons of interest. It was then possible to accurately measure the long-range proton carbon coupling constants from the overlaid $\alpha / \beta$ datasets (Figure 3C). A more-detailed description of this procedure can be found in the Supporting Information [19]. The heteronuclear $J$ couplings measured in this experiment in DMSO- $d_{6}$ were ${ }^{3} J_{\mathrm{H}-3, \mathrm{C}-16}=1.9 \mathrm{~Hz}$ and ${ }^{3} \mathrm{~J}_{\mathrm{H}-4, \mathrm{C}-6}=5.4 \mathrm{~Hz}$. This $J$-based analysis confirmed that the substitution of the oxolane ring in 1 is $\mathrm{H}-4 / \mathrm{C}-6$ cis, $\mathrm{H}-3 / \mathrm{C}-16$ trans, and $\mathrm{H}-3 / \mathrm{H}-4$ trans orientation (Figure 3D, Supporting Information). The relative configuration of $\mathbf{1}$ was thus determined to be $2 R^{*}, 3 R^{*}, 4 R^{*}$, and $5 S^{*}$. The absolute configuration of suberitamide A (1) could not be assigned by computational methods as there was no observable Cotton effect in the experimental ECD profile, and due to sidechain mobility and puckering of the central five-membered ring, 62 different conformers resulted from a conformational search using Macromodel software (version 12.0.012, Schrödinger Inc., New York, NY, USA).
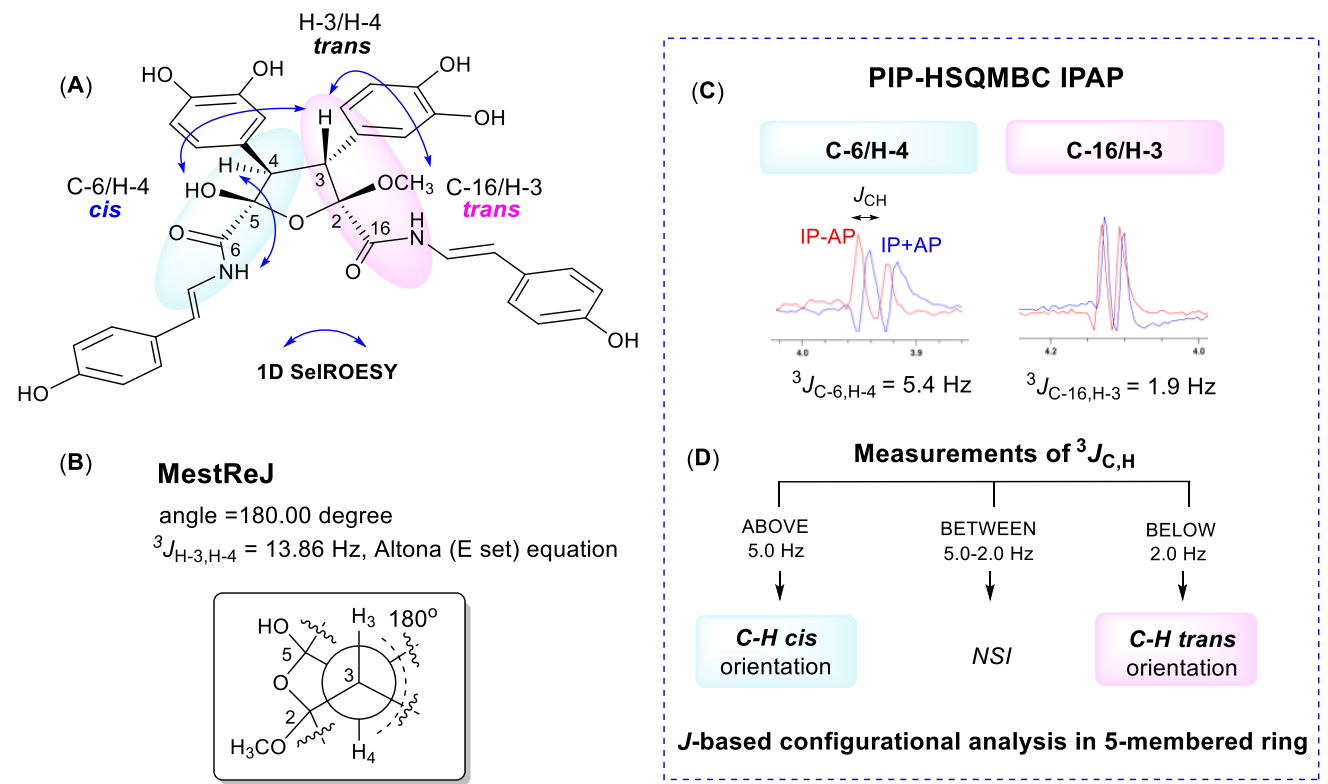

Figure 3. (A) Selective 1D ROESY correlations around the five-membered ring in 1. (B) calculated proton-proton coupling when the $\mathrm{H}-3 / \mathrm{H}-4$ dihedral angle is $180^{\circ}$. (C) $8.0 \mathrm{~Hz}$ optimized PIP-HSQMBC IPAP (pure in-phase heteronuclear single quantum multiple bond correlation in-phase and anti-phase) spectra were acquired. The in-phase plus anti-phase (IP + AP) and in-phase minus anti-phase (IP - AP) datasets were processed and corresponding $1 \mathrm{D}$ slices (blue, IP + AP; red, IP - AP) were overlaid at the C-3, C-4, C-6, and C-16 carbon chemical shifts. (D) flow chart to use ${ }^{3} J_{C, H}$ values for configurational analysis of five-membered oxolane ring (NSI: no stereochemical information can be extracted) [14,15]. 
The molecular formula of suberitamide B (2) was established as $\mathrm{C}_{42} \mathrm{H}_{35} \mathrm{~N}_{3} \mathrm{O}_{9}$ by HRESIMS analysis with 27 degrees of unsaturation, while observation of only half of the predicted signals in the ${ }^{1} \mathrm{H}$ and ${ }^{13} \mathrm{C}$ NMR spectra (Table 2) revealed it was a symmetrical molecule. Comparison with the NMR data for 1 showed there were appropriate signals for two symmetrical para-hydroxystyrylamide $(p H S A)$ and 3,4-dihydroxyphenyl groups in 2 . In addition, the presence of a tyramine unit in 2 was indicated by a pair of aromatic doublets at $\delta_{\mathrm{H}} 6.99(2 \mathrm{H}, \mathrm{d}, J=8.4 \mathrm{~Hz})$ and $6.68(2 \mathrm{H}, \mathrm{d}, J=8.4 \mathrm{~Hz})$ and a pair of broad triplets at $\delta_{\mathrm{H}} 4.69(2 \mathrm{H}$, br t, $J=7.6 \mathrm{~Hz})$ and $2.99(2 \mathrm{H}, \mathrm{br}, J=7.6 \mathrm{~Hz})$ in $\mathrm{MeOH}-d_{4}$. The structural fragments assembled thus far accounted for 24 degrees of unsaturation, and only two pairs of equivalent $\mathrm{sp}^{2}$ carbons $\left(\delta_{\mathrm{C}} 127.8\right.$ and 127.9) were left to account for the three remaining double bond equivalents. Considering the symmetry and molecular formula requirements, the remaining fragment was a fully substituted pyrrole ring formed with the nitrogen of the tyramine moiety. The structure of suberitamide B (2) was assigned with the two enamide carbonyls attached at C-2 and C-5 of the pyrrole, the two 3,4-dihydroxyphenyl rings substituted at C-3 and C-4, and a tyramine moiety with the nitrogen incorporated into the central pyrrole ring. This assignment was supported by HMBC correlations from H-37 to C-2/C-5, H-27/H-31 to C-3, and H-33/37 to C-4 (Figure 4). Suberitamide B (2) is structurally related to the storniamides, which are nonsymmetrical pyrrole-containing aryl alkaloids reported from a Cliona sp. marine sponge collected in Patagonia [20].

Table 2. ${ }^{13} \mathrm{C}$ NMR (150 MHz) and ${ }^{1} \mathrm{H}$ NMR (600 MHz) Data for suberitamides B (2) and C (3) in CD ${ }_{3} \mathrm{OD}$.

\begin{tabular}{|c|c|c|c|c|}
\hline \multirow[b]{2}{*}{ Position } & \multicolumn{2}{|r|}{2} & \multicolumn{2}{|c|}{3} \\
\hline & $\delta_{C}$ (type) & $\delta_{\mathrm{H}}(J$ in $\mathrm{Hz})$ & $\delta_{C}$ (type) & $\delta_{\mathrm{H}}(J$ in $\mathrm{Hz})$ \\
\hline 2,5 & 127.9, C & & 197.2, C & \\
\hline 3,4 & $127.8, \mathrm{C}$ & & $55.5, \mathrm{CH}$ & $5.15, \mathrm{~s}$ \\
\hline 6,16 & 161.1, C & & $159.3, \mathrm{C}$ & \\
\hline 8,18 & $120.5, \mathrm{CH}$ & 7.27, d (14.6) & $120.0, \mathrm{CH}$ & 7.14, d (14.6) \\
\hline 9,19 & $115.6, \mathrm{CH}$ & $5.71, \mathrm{~d}(14.6)$ & 118.6, $\mathrm{CH}$ & $6.42, \mathrm{~d}(14.6)$ \\
\hline 10,20 & $128.8, \mathrm{C}$ & & $128.7, \mathrm{C}$ & \\
\hline $11,15,21,25$ & $127.8, \mathrm{CH}$ & $7.11, \mathrm{~d}(8.4)$ & $128.1, \mathrm{CH}$ & $7.18, \mathrm{~d}(8.4)$ \\
\hline $12,14,22,24$ & $116.5, \mathrm{CH}$ & $6.69, \mathrm{~d}(8.4)$ & $116.5, \mathrm{CH}$ & $6.70, \mathrm{~d}(8.4)$ \\
\hline 13,23 & 157.7, C & & 158.1, C & \\
\hline 26,32 & $126.3, \mathrm{C}$ & & $125.8, \mathrm{C}$ & \\
\hline 27,33 & $118.6, \mathrm{CH}$ & $6.61, \mathrm{~d}(1.8)$ & 117.7, $\mathrm{CH}$ & $6.53, \mathrm{~d}(1.6)$ \\
\hline 28,34 & 146.3, C & & $146.5, \mathrm{C}$ & \\
\hline 29,35 & 145.9, C & & $146.1, \mathrm{C}$ & \\
\hline 30,36 & $116.4, \mathrm{CH}$ & $6.74, \mathrm{~d}(8.4)$ & $116.5, \mathrm{CH}$ & $6.60, \mathrm{~d}(8.4)$ \\
\hline 31,37 & $123.2, \mathrm{CH}$ & 6.53, dd $(8.4,1.8)$ & $122.1, \mathrm{CH}$ & $6.42, \mathrm{dd}(8.4,1.6)$ \\
\hline 38 & $49.3, \mathrm{CH}_{2}$ & 4.69, br t $(7.6)$ & & \\
\hline 39 & 38.7, $\mathrm{CH}_{2}$ & 2.99, br t $(7.6)$ & & \\
\hline 40 & $130.5, \mathrm{C}$ & & & \\
\hline 41,45 & $131.2, \mathrm{CH}$ & $6.99, \mathrm{~d}(8.4)$ & & \\
\hline 42,44 & $116.2, \mathrm{CH}$ & $6.68, \mathrm{~d}(8.4)$ & & \\
\hline 43 & $157.2, \mathrm{C}$ & & & \\
\hline
\end{tabular}

The molecular formula of suberitamide $\mathrm{C}$ (3) was established as $\mathrm{C}_{34} \mathrm{H}_{28} \mathrm{~N}_{2} \mathrm{O}_{10}$ by HRESIMS measurements, with 22 degrees of unsaturation. Detailed examination of the ${ }^{1} \mathrm{H}$ and ${ }^{13} \mathrm{C}$ NMR data, aided by 2D NMR experiments, revealed this compound was also a symmetrical molecule. Characteristic NMR signals for para-hydroxystyrylamide and 3,4-dihydroxyphenyl groups were apparent, as well 
as an aliphatic methine $\left(\delta_{\mathrm{H}} 5.15 / \delta_{\mathrm{C}} 55.5\right)$ and a ketone carbonyl $\left(\delta_{\mathrm{C}} 197.2\right)$. HMBC correlations from the methine proton linked the methine group to a 3,4-dihydroxyphenyl moiety and to the ketone carbon (Figure 4). This suggested that suberitamide $C$ (3) was a symmetrical, ring-opened homologue where the oxolane ring of $\mathbf{1}$ was opened and the C-2 and C-5 carbons were both ketones. An HMBC correlation from the aliphatic methine proton to the methine carbon supported the conclusion that two symmetrical subunits of $\mathbf{3}$ were linked via the methine carbons. The configuration of the methine carbons in suberitamide $C(3)$ was assigned by analogy with 1 . Consistent with this assumption of either $3 R, 4 R$ or $3 S, 4 S$ stereochemistry, compound 3 was optically active $([\alpha] 25 D+86.7)$, while a meso form $(3 R, 4 S$ or $3 S, 4 R)$ of 3 would be achiral. The $\alpha$-ketoenamide functionality found in suberitamide $C$ (3) is an unusual structural feature for a natural product, and while a close relationship between 1 and $\mathbf{3}$ is apparent, compound $\mathbf{1}$ was stable and no conversion of $\mathbf{1}$ to $\mathbf{3}$ was observed over an extended period of time and in variety of solvents.

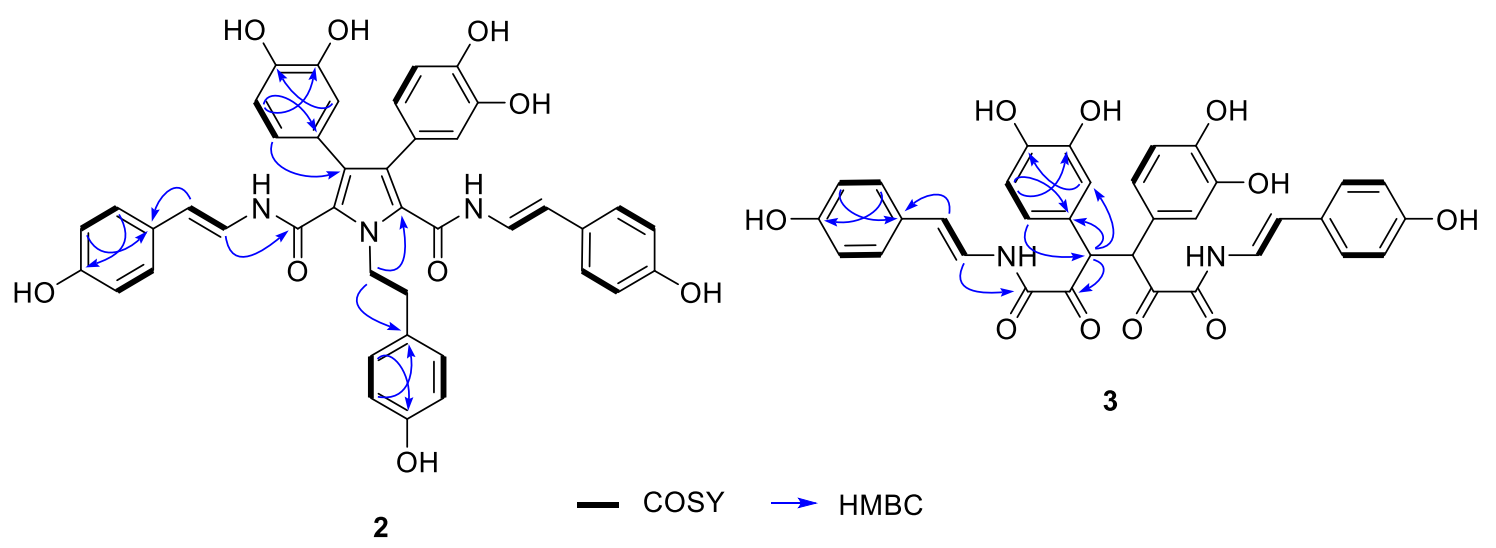

Figure 4. Selected 2D NMR correlations for suberitamides B (2) and C (3).

Suberitamides A-C (1-3) were tested for their ability to inhibit autoubiquitination of the E3 ubiquitin ligase Cbl-b [10]. Compounds $\mathbf{1}$ and 2, with cyclic central cores comprised of oxolane and pyrrole rings, respectively, abrogated Cbl-b enzymatic activity with low micromolar potencies. The $\mathrm{EC}_{50}$ value for both 1 and $\mathbf{2}$ was approximately $11 \mu \mathrm{M}$, while the ring-opened homologue $\mathbf{3}$ was inactive at a high-test concentration of $64 \mu \mathrm{M}$ (Figure 5). This suggests that the structural rigidity imparted by the cyclized core of $\mathbf{1}$ and $\mathbf{2}$ is necessary for activity, since the more flexible, ring-opened derivative 3 is inactive. Cbl-b functions as a negative regulator of immune activation, thus it represents an attractive potential target for immune system modulation. Inhibitors of $\mathrm{Cbl}-\mathrm{b}$ could have therapeutic applications such as enhancing the innate anticancer immune response. While several natural products with Cbl-b inhibitory properties have been reported, they generally are cationic metabolites with quaternary amine groups [10]. Suberitamides A (1) and B (2), which do not have fixed positive charges, represent a new class of $\mathrm{Cbl}-\mathrm{b}$ inhibitors that could provide a structural framework for further therapeutic development. 


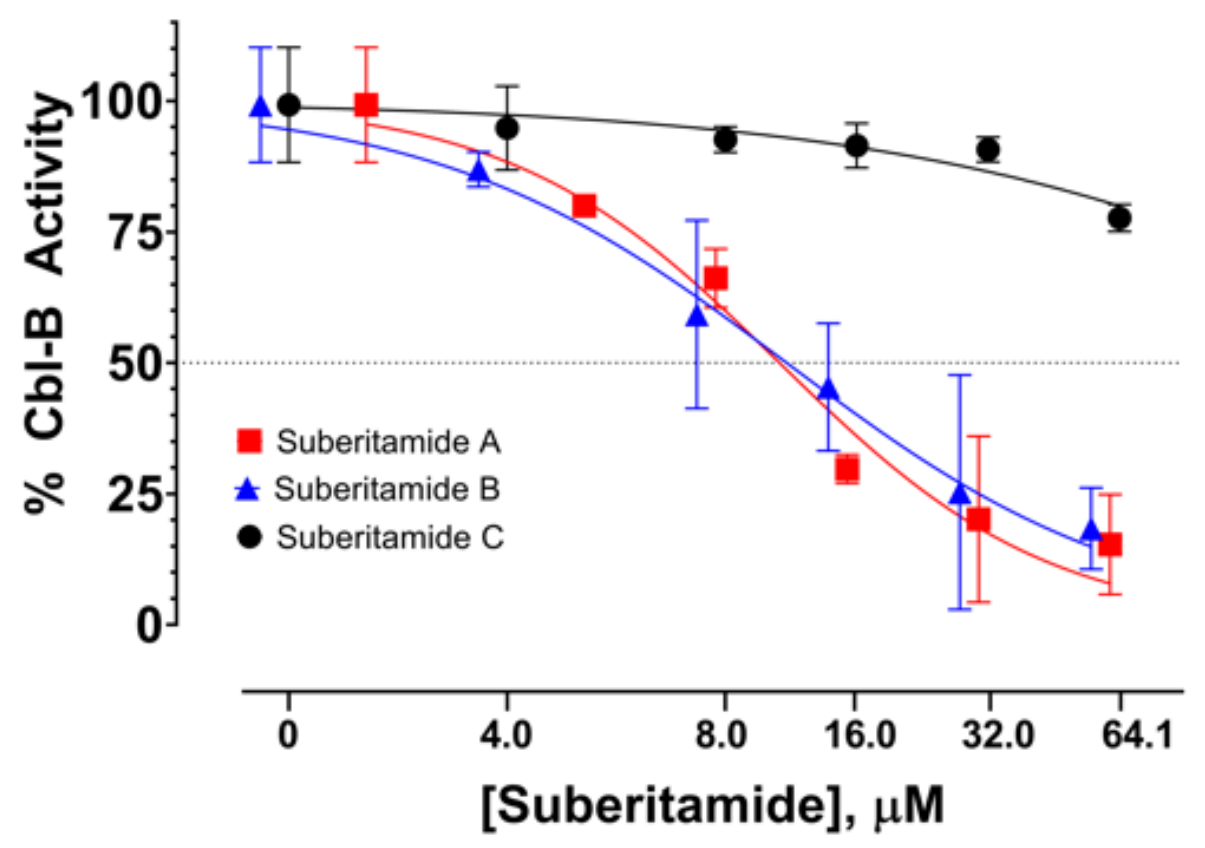

Figure 5. Dose-response curves of Cbl-b inhibitory activity for suberitamides A-C (1-3).

\section{Materials and Methods}

\subsection{General Experimental Procedures}

Optical rotations were measured on a Rudolph research analytical AUTOPOL IV automatic polarimeter (Rudolph Research Analytical, Hackettstown, NJ, USA), IR spectra were recorded with a Bruker ALPHA II FT-IR spectrometer (Bruker, Billerica, MA, USA), and UV spectra were measured with a Thermo Scientific Nanodrop 2000C spectrophotometer (Thermo Fisher Scientific, Waltham, MA, USA). High-performance liquid chromatography (HPLC) was performed using a Varian ProStar 215 solvent delivery module equipped with a Varian Prostar 320 UV-Vis detector (Agilent Technologies, Santa Clara, CA, USA), operating under Star 6.41 chromatography workstation software (6.41, Agilent Technologies, Santa Clara, CA, USA). NMR spectra were obtained with a Bruker Avance III NMR spectrometer (Bruker, Billerica, MA, USA) equipped with a $3 \mathrm{~mm}$ cryogenic probe and operating at $600 \mathrm{MHz}$ for ${ }^{1} \mathrm{H}$ and $150 \mathrm{MHz}$ for ${ }^{13} \mathrm{C}$. Spectra were calibrated to residual solvent signals at $\delta_{\mathrm{H}} 2.50$ and $\delta_{\mathrm{C}} 39.5\left(\mathrm{DMSO}-d_{6}\right)$, and $\delta_{\mathrm{H}} 3.31$ and $\delta_{\mathrm{C}} 49.0\left(\mathrm{CD}_{3} \mathrm{OD}\right)$. All 2D NMR experiments were acquired with nonuniform sampling (NUS) set to $50 \%$ or $25 \%$. HMBC experiments were run with ${ }^{n} J_{C H}=8.0,3.5$, or $2.0 \mathrm{~Hz}$, and the LR-HSQMBC experiment was optimized for ${ }^{\mathrm{n}} J_{\mathrm{CH}}=2.0 \mathrm{~Hz}$. HRESIMS data were acquired on an Agilent Technology 6530 Accurate-mass Q-TOF LC/MS (Agilent Technologies, Santa Clara, CA, USA).

\subsection{Animal Material}

Samples of the marine sponge Pseudosuberites sp. were collected by scuba at a depth of $\sim 2.5 \mathrm{~m}$ from a hard substrate at Harkers Island, North Carolina, USA, and kept frozen until extraction. The collection was carried out by Sea Samples, for the Coral Reef Research Foundation, under contract with the National Products Branch, U.S. National Cancer Institute. A voucher specimen (voucher ID \# 0YYD 3440) was deposited at the Smithsonian Institution, Washington, DC, USA.

\subsection{Extraction and Isolation}

The animal material (442 $\mathrm{g}$ wet wt.) was ground and processed using the standard NCI method for marine samples to provide $17.2 \mathrm{~g}$ of organic solvent extract (NSC C032671) [21]. A $5.1 \mathrm{~g}$ aliquot of the Pseudosuberites sp. organic extract was subjected to $\mathrm{C}_{18}$ reversed-phase flash column chromatography 
using a step gradient elution with $100 \%$ hexane (fraction $\mathrm{A}, 195 \mathrm{mg}$ ), $100 \% \mathrm{CH}_{2} \mathrm{Cl}_{2}$ (fraction $\mathrm{B}, 647 \mathrm{mg}$ ), 100\% EtOAc (fraction C, $274 \mathrm{mg}$ ), 100\% acetone (fraction D, $590 \mathrm{mg}$ ), and 100\% MeOH (fraction E, $2.96 \mathrm{~g}$ ). The active fraction $\mathrm{C}$ was separated by preparative reversed-phase HPLC (Agilent Dynamax C18 column, $21.4 \mathrm{~mm} \times 250 \mathrm{~mm}$, Santa Clara, CA, USA) eluting at $9 \mathrm{~mL} / \mathrm{min}$ with a $\mathrm{CH}_{3} \mathrm{CN}_{-} \mathrm{H}_{2} \mathrm{O}$ gradient (20:80-60:40), yielding $\left(t_{\mathrm{R}}=62 \mathrm{~min}\right)$ compound $2(2.9 \mathrm{mg})$, as an amorphous oil. Further purification of the sub-fractions (11 and 12) by semi-preparative reversed-phase HPLC (Phenomenex Luna C18 column, $10 \mathrm{~mm} \times 250 \mathrm{~mm}$, Torrance, CA, USA) eluting at $3.0 \mathrm{~mL} / \mathrm{min}$ with a $\mathrm{CH}_{3} \mathrm{CN}-\mathrm{H}_{2} \mathrm{O}$ gradient (28:72-50:50), $t_{\mathrm{R}}=51 \mathrm{~min}$, and $\mathrm{CH}_{3} \mathrm{CN}-\mathrm{H}_{2} \mathrm{O}$ gradient (35:65-65:35), $t_{\mathrm{R}}=23 \mathrm{~min}$, afforded compounds $3(0.7 \mathrm{mg})$ and $\mathbf{1}(3.4 \mathrm{mg})$, respectively, as amorphous powders.

Suberitamide $A$ (1): yellow, amorphous powder; $[\alpha] 25 D+7.5(c 0.11, \mathrm{MeOH})$; UV (MeOH) $\lambda_{\max }$

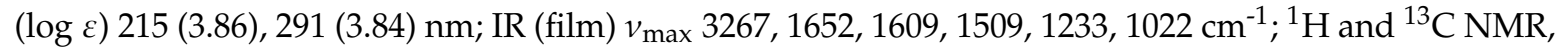
Table 1; HRESIMS m/z 657.2090 [M + H] ${ }^{+}$(calcd for $\mathrm{C}_{35} \mathrm{H}_{33} \mathrm{~N}_{2} \mathrm{O}_{11}, 657.2084$ )

Suberitamide B (2): yellow, amorphous powder; UV (MeOH) $\lambda_{\max }(\log \varepsilon) 217$ (4.19), 292 (3.96), 337 (3.97) nm; IR (film) $v_{\max } 3339,1649,1608,1503,1240,1200 \mathrm{~cm}^{-1} ;{ }^{1} \mathrm{H}$ and ${ }^{13} \mathrm{C}$ NMR, Table 2; HRESIMS $m / z 726.2447[\mathrm{M}+\mathrm{H}]^{+}$(calcd for $\mathrm{C}_{42} \mathrm{H}_{36} \mathrm{~N}_{3} \mathrm{O}_{9}, 726.2452$ )

Suberitamide C (3): yellow, amorphous powder; $[\alpha] 25 \mathrm{D}+86.7(c 0.06, \mathrm{MeOH}) ; \mathrm{UV}(\mathrm{MeOH}) \lambda_{\max }$ $(\log \varepsilon) 217$ (3.48), $288(3.44) \mathrm{nm}$; IR (film) $v_{\max } 3300,1677,1608,1512,1207,1139 \mathrm{~cm}^{-1} ;{ }^{1} \mathrm{H}$ and ${ }^{13} \mathrm{C}$ NMR, Table 2; HRESIMS m/z 625.1808 $[\mathrm{M}+\mathrm{H}]^{+}\left(\right.$calcd for $\mathrm{C}_{34} \mathrm{H}_{29} \mathrm{~N}_{2} \mathrm{O}_{10}, 625.1820$ )

\subsection{Calculation of Dihedral Bond Angles in MestReJ}

Calculation of the dihedral angle between $\mathrm{H}-3$ and $\mathrm{H}-4$ was performed using the Altona equation with 4 substituents at the C-3 and C-4 positions. The resulting ${ }^{3} \mathrm{~J}_{\mathrm{H}-3, \mathrm{H}-4}$ value for a $180^{\circ}$ dihedral angel was $13.9 \mathrm{~Hz}$ [16].

\subsection{NMR Measurements}

The HSQC-HECADE (heteronuclear couplings from ASSCI-domain experiments with E.COSYtype cross peaks) experiment was recorded using DIPSI (decoupling in the presence of scalar interactions) during the $40 \mathrm{~ms}$ isotropic mixing period, using a bandwidth of $10 \mathrm{kHz}$ and a J-scale factor of 1 . Prior to Fourier transformation, zero filling was performed to expand the data to at least double the number of acquired data points. The PIP-HSQMBC spectra were recorded with an inter-pulse delay optimized to $8 \mathrm{~Hz}\left(\Delta=1 / 2 \times{ }^{\mathrm{n}} J_{\mathrm{CH}}=62.5 \mathrm{~ms}\right)$. The recycle delay was $1 \mathrm{~s}$ and 256 scans were collected for each of the $64 t_{1}$ increments, with 4096 data points in each $t_{1}$ increment. Prior to Fourier transformation, zero-filling to 1024 points in F1, 8192 points in F2 and a squared sine-bell apodization phase-shifted $90^{\circ}$ in both dimensions was applied. The final digital resolution along the detected F2 dimension was of $0.4 \mathrm{~Hz}$. The total experimental time was about $6 \mathrm{~h} 22 \mathrm{~min} 53 \mathrm{~s}$ for each IP and AP dataset. For the IPAP technique, IP and AP-HSQMBC datasets were separately recorded and then added/subtracted in the time-domain to provide two separate $\alpha / \beta$ data sets. Additional fitting processes, simulations, and experimental spectra are available in the Supporting Information.

\subsection{Cbl-b Biochemical Assay}

Details of the Cbl-b assay system have been described previously [10]. In brief, dose response experiments with the purified compounds were carried out in Tris- $\mathrm{HCl}$ buffer $(\mathrm{pH} 7.5)$ that contained $15 \mathrm{nM}$ E1 protein (UBE1), $75 \mathrm{nM}$ E2 protein (UBC-H5) [22], $112 \mathrm{nM} \mathrm{Cbl-b}$ protein (N1/2 Construct) [23], $75 \mathrm{nM}$ biotinylated ubiquitin, $750 \mathrm{nM}$ ubiquitin, $0.1 \mathrm{mM}$ dithiothreitol, $0.5 \mathrm{mg} / \mathrm{mL}$ bovine gelatin type B, $0.5 \mathrm{mM}$ magnesium chloride, and 0.01\% Triton X-100. Addition of ATP into the enzyme solution initiated the enzymatic reaction cascade. Initiated reactions were then transferred to plates that had been precoated overnight with $10 \mu \mathrm{g} / \mathrm{mL}$ of the polyubiquitin binding portion of Cbl-b (UBA) [24] which allowed for the binding and specific enrichment of autopolyubiquitinated Cbl-b. After $1 \mathrm{~h}$, the reactions were quenched and the reaction plates were sealed and incubated overnight at room temperature. The following day, reaction plates were probed with avidin-conjugated horse radish peroxidase, 
washed three times, and then an avidin-HRP dependent fluorescent signal (indicating the presence of avidin-HRP/biotin-polyubiquitin complexes bound by the UBA-coated plate) was detected (excitation $325 \mathrm{~nm}$, emission $420 \mathrm{~nm}$ ) using a Tecan Infinite M1000 plate reader (Tecan, Zürich, Switzerland) Fluorescence data for each test well was background corrected and normalized to its vehicle control according to the following formula:

$$
\% \text { Activity }=\frac{(\text { Substance RFU }- \text { DMSO Control }}{\text { No ATP })} \underset{\left(\text { DMSO Control }_{+A T P}-\right.\text { DMSO Control }}{\text { No ATP })} * 100
$$

\section{Conclusions}

Chemical investigation of the sponge Pseudosuberites sp. provided three new aryl alkaloids named suberitamides A-C (1-3). Structure elucidation of suberitamide A (1) was aided by the application of new NMR methodologies including the PIP HSQMBC IPAP experiment [11] for measuring key long-range heteronuclear $(\mathrm{C}, \mathrm{H})$ coupling constants. This allowed unambiguous assignment of the relative configuration of the four contiguous stereogenic centers in the flexible oxolane ring of 1. Suberitamides B (2) and C (3) are structurally related symmetrical molecules and 3 possesses $\alpha$-ketoenamide functionalities, which are rare in natural products. In a biochemical assay for inhibitors of the ubiquitin ligase Cbl-b, suberitamides A (1) and B (2), with aryl-substituted oxolane and pyrrole central rings, respectively, were active at low micromolar concentrations, while the ring-opened derivative 3 was inactive. The suberitamides represent a new class of natural product inhibitors of Cbl-b ubiquitin ligase activity that are structurally distinct from other known inhibitors of this enzyme.

Supplementary Materials: The following are available online at http://www.mdpi.com/1660-3397/18/11/536/s1, Experimental procedures, additional figures, and full spectroscopic data for compounds 1-3.

Author Contributions: C.-K.K. purified the compounds, solved their structures, and contributed to manuscript writing. D.W. and J.S. contributed to NMR data collection and interpretation. B.A.P.W., D.V., S.L. and B.R.O. contributed to Cbl-b assay development and screening. K.R.G. was the project leader and contributed to structure elucidation and manuscript writing. All authors have read and agreed to the published version of the manuscript.

Funding: This research received no external funding.

Acknowledgments: Grateful acknowledgement goes to the Natural Products Support Group (NCI at Frederick) for extract preparation and to the recombinant protein production efforts of Lauren Procter, Morgan Pagonis, and Jane Jones of the Protein Expression Laboratory at the Frederick National Laboratory for Cancer Research. This research was funded in part by the Intramural Research Program of the NIH, National Cancer Institute, Center for Cancer Research. The content of this publication does not necessarily reflect the views or policies of the Department of Health and Human Services, nor does mention of trade names, commercial products, or organizations imply endorsement by the U.S. Government.

Conflicts of Interest: The authors declare no conflict of interest.

\section{References}

1. Paolino, M.; Choidas, A.; Wallner, S.; Pranjic, B.; Uribesalgo, I.; Loeser, S.; Jamieson, A.M.; Langdon, W.Y.; Ikeda, F.; Fededa, J.P.; et al. The E3 ligase Cbl-b and TAM receptors regulate cancer metastasis via natural killer cells. Nature 2014, 507, 508-512. [CrossRef] [PubMed]

2. Lutz-Nicoladoni, C.; Wolf, D.; Sopper, S. Modulation of immune cell functions by the E3 ligase Cbl-b. Front. Oncol. 2015, 5, 1-14. [CrossRef] [PubMed]

3. Bachmaier, K.; Krawczyk, C.; Kozieradzki, I.; Kong, Y.-Y.; Sasaki, T.; Oliveira-Dos-Santos, A.; Mariathasan, S.; Bouchard, D.; Wakeham, A.; Itie, A.; et al. Negative regulation of lymphocyte activation and autoimmunity by the molecular adaptor Cbl-b. Nature 2000, 403, 211-216. [CrossRef] [PubMed]

4. Chiang, Y.J.; Kole, H.K.; Brown, K.; Naramura, M.; Fukuhara, S.; Hu, R.-J.; Jang, I.K.; Gutkind, J.S.; Shevach, E.; $\mathrm{Gu}, \mathrm{H}$. Cbl-b regulates the CD28 dependence of T-cell activation. Nature 2000, 403, 216-220. [CrossRef]

5. Tang, R.; Langdon, W.Y.; Zhang, J. Regulation of immune responses by E3 ubiquitin ligase Cbl-b. Cell. Immunol. 2019, 340, 103878. [CrossRef]

6. Kales, S.C.; Ryan, P.E.; Nau, M.M.; Lipkowitz, S. Cbl and human myeloid neoplasms: The Cbl oncogene comes of age. Cancer. Res. 2010, 70, 4789-4794. [CrossRef] 
7. Wallner, S.; Gruber, T.; Baier, G.; Wolf, D. Releasing the brake: Targeting Cbl-b to enhance lymphocyte effector functions. Clin. Dev. Immunol. 2012, 692639. [CrossRef]

8. Thornburg, C.C.; Britt, J.R.; Evans, J.R.; Akee, R.K.; Whitt, J.A.; Trinh, S.K.; Harris, M.J.; Thompson, J.R.; Ewing, T.L.; Shipley, S.M.; et al. NCI program for natural product discovery: A publicly-accessible library of natural product fractions for high-throughput screening. ACS Chem. Biol. 2018, 13, 2484-2497. [CrossRef]

9. Grkovic, T.; Akee, R.K.; Thornburg, C.C.; Trinh, S.; Britt, J.R.; Harris, M.J.; Evans, J.; Kang, U.; Ensel, S.; Henrich, C.J.; et al. National Cancer Institute (NCI) Program for Natural Products Discovery: Rapid isolation and identification of biologically active natural products from the NCI prefractionated library. ACS Chem. Biol. 2020, 15, 1104-1114. [CrossRef]

10. Wilson, B.A.P.; Voeller, D.; Smith, E.A.; Wamiru, A.; Liu, G.; Lipkowitz, S.; O’Keefe, B.R. Methyl-ellipticiniums as inhibitors of the CBLB ubiquitin ligase. ACS Pharmacol. Transl. Sci. 2020. submitted.

11. Castañar, L.; Saurí, J.; Williamson, R.T.; Virgili, A.; Parella, T. Pure in-phase heteronuclear correlation NMR experiments. Angew. Chem. Int. Ed. 2014, 53, 8379-8382. [CrossRef] [PubMed]

12. Williamson, R.T.; Buevich, A.V.; Martin, G.E.; Parella, T. LR-HSQMBC: A sensitive NMR technique to probe very long-range heteronuclear coupling pathways. J. Org. Chem. 2014, 79, 3887-3894. [CrossRef] [PubMed]

13. Costantino, V.; Fattorusso, E.; Imperatore, C.; Mangoni, A. Glycolipids from sponges. 20. J.-coupling analysis for stereochemical assignments in furanosides: Structure elucidation of vesparioside B, a glycosphingolipid from the marine sponge Spheciospongia vesparia. J. Org. Chem. 2008, 73, 6158-6165. [CrossRef]

14. Gutiérrez-Cepeda, A.; Daranas, A.H.; Fernández, J.J.; Norte, M.; Souto, M.L. Stereochemical determination of five-membered cyclic ether acetogenins using a spin-spin coupling constant approach and DFT calculations. Mar. Drugs 2014, 12, 4031-4044. [CrossRef]

15. Napolitano, J.G.; Gavín, J.A.; García, C.; Norte, M.; Fernández, J.J.; Daranas, A.H. On the configuration of five-membered rings: A spin-spin coupling constant approach. Chem. Eur. J. 2011, 17, 6338-6347. [CrossRef]

16. Navarro-Vazquez, A.; Cobas, J.C.; Sardina, F.J. A graphical tool for the prediction of vicinal proton-proton ${ }^{3} J_{\mathrm{HH}}$ coupling constants. J. Chem. Inf. Comput. Sci. 2004, 44, 1680-1685. [CrossRef]

17. Kozminski, W.; Nanz, D. HECADE: HMQC-and HSQC-based 2D NMR experiments for accurate and sensitive determination of heteronuclear coupling constants from E.COSY-type cross peaks. J. Magn. Reson. 1997, 124, 383-392. [CrossRef]

18. Kozminski, W.; Nanz, D. Sensitivity improvement and new acquisition scheme of heteronuclear active-coupling-pattern-tilting spectroscopy. J. Magn. Reson. 2000, 142, 294-299. [CrossRef]

19. Saurí, J.; Nolis, P.; Parella, T. How to measure long-range proton-carbon coupling constants from ${ }^{1} \mathrm{H}$-selective HSQMBC experiments. Magn. Reson. Chem. 2020, 58, 363-375. [CrossRef]

20. Palermo, J.A.; Brasco, M.F.R.; Seldes, A.M. Storniamides A-D: Alkaloids from a Patagonian sponge Cliona sp. Tetrahedron 1996, 52, 2727-2734. [CrossRef]

21. McCloud, T.G. High throughput extraction of plant, marine and fungal specimens for preservation of biologically active molecules. Molecules 2010, 15, 4526-4563. [CrossRef]

22. Lorick, K.L.; Jensen, J.P.; Fang, S.; Ong, A.M.; Hatakeyama, S.; Weissman, A.M. RING fingers mediate ubiquitin-conjugating enzyme (E2)-dependent ubiquitination. Proc. Natl. Acad. Sci. USA 1999, 96, 11364-11369. [CrossRef]

23. Ettenberg, S.A.; Magnifico, A.; Cuello, M.; Nau, M.M.; Rubinstein, Y.R.; Yarden, Y.; Weissman, A.M.; Lipkowitz, S. Cbl-b dependent coordinated degradation of the epidermal growth factor receptor signaling complex. J. Biol. Chem. 2001, 276, 27677-27684. [CrossRef]

24. Davies, G.C.; Ettenberg, S.A.; Coats, A.O.; Mussante, M.; Ravichandran, S.; Collins, J.; Nau, M.M.; Lipkowitz, S. Cbl-b interacts with ubiquitinated proteins; differential functions of the UBA domains of c-Cbl and Cbl-b. Oncogene 2004, 23, 7104-7115. [CrossRef]

Publisher's Note: MDPI stays neutral with regard to jurisdictional claims in published maps and institutional affiliations. 